\title{
Public News and Market Liquidity: Evidence from the CDS Market*
}

\author{
Wei-Fong Pan \\ University of Reading \\ wei-fong.pan@pgr.reading.ac.uk \\ Xinjie Wang \\ Southern University of Science and Technology \\ xinjie.wang@sustech.edu.cn \\ Shanxiang Yang \\ Southern University of Science and Technology \\ yangsx@mail.sustech.edu.cn \\ Jinfan Zhang \\ The Chinese University of Hong Kong (Shenzhen) \\ zhangjinfan@cuhk.edu.cn \\ Zhaodong (Ken) Zhong \\ Rutgers University \\ zdzhong@business.rutgers.edu
}

February 9, 2020

Keywords: credit default swap, liquidity, news coverage, news sentiment, institutional investors JEL classification: G10, G12, G14

\footnotetext{
* We are grateful for the valuable comments from Yiwei Deng, Yue Liu, Xiangang Xin, Zhaobo Zhu and participants at the 1st Guangdong-Hong Kong-Macao Area Research Forum on Business, the 8th International Conference on Futures and Other Derivatives, the 5th International Conference on Fintech Development, and the Accounting and Business Research (ABR) and China Journal of Accounting Research (CJAR) Joint Conference. All remaining errors are our own. Xinjie Wang acknowledges financial support from the Southern University of Science and Technology (Grant No. Y01246210, Y01246110).
} 


\title{
Public News and Market Liquidity: Evidence from the CDS Market
}

\begin{abstract}
This paper examines the effects of public news releases on the market liquidity in one of the most important OTC derivatives markets-the CDS market. We document that, at the time of news releases, the bid-ask spread is wider, the number of quotes is larger, and the number of dealers is greater. Earnings announcements have particularly strong effects on liquidity while news related to credit ratings has no significant effects. Moreover, the bid-ask spread only increases on news release days and reverts to normal levels several days after news releases. Finally, the effect of news on liquidity is stronger for negative, fundamental, and unscheduled news, and is more pronounced among firms with higher information asymmetry. Our findings are consistent with models of rational trade in Kim and Verrecchia (1994).
\end{abstract}




\section{Introduction}

One important role of media is to disseminate informaiton about firms to market participants. Prior studies find that the release of public financial news generally reduces information asymmetries among market participants and thus increases market liquidity (e.g., Diamond and Verrecchia, 1991; Tetlock, 2010, among others). In some market environments, however, it has been shown that the release of financial news creates temporary information asymmetry and deceases market liquidity (e.g., Harris and Raviv, 1993; Kim and Verrecchia, 1991, 1994, 1997). Although the prior literature has examined the impact of news on liquidity in the equity market, there is still little research dedicated to exploring the relationship between news releases and the liquidity in the over-the-counter (OTC) derivatives markets, which have gained a lot of attendtion in recent years not only due to their enormous sizes, but also their important roles in the global financial system. This study aims to fill this important gap by investigating the effects of public financial news on the liquidity in one of the most important OTC derivative marketsthe credit default swap (CDS) market.

We focus on the CDS market for two main reasons. First, CDS is often considered as an obscure instrument that is one of the main culprits of the last global financial crisis. Therefore, a better understanding of how public news affects liquidity in the CDS market is not only an important research topic, but also has crucial policy implications. Second, the CDS market has some unique features that are different from the equity market. For example, the CDS market is predominantly a dealer market where dealers provide liquidity to institutional investors. Moreover, since CDS contracts are typically traded with at least $\$ 10$ million in notional value, investors in the CDS market are exclusively institutional investors and virtually no retail 
investors are present there. Therefore, most trades are between dealers and sophisticated institutional investors in the CDS market. ${ }^{1}$ This allows us to isolate the response of institutional investors to public news and conduct tests using a framework closer to the settings of theoretical models.

Public news releases could affect CDS market liquidity in several aspects. Kim and Verrecchia $(1991,1994)$ develop a model of rational trade and predict that news releases create temporary informaiton asymmetry and thus increase the bid-ask spread. Despite the temporary decrease in liquidity, trading volume also increases due to heterogeneous beliefs among traders induced at the time of news releases. We formulate these predictions into three hypotheses for our study in the CDS market. First, the bid-ask spread on CDS spreads increases at the time of public news releases. Second, the number of pricing quotes increases at the time of public news releases. Third, the number of dealers also increases at the time of public news releases.

We obtain news data from RavenPack News Analytics, a data vendor that provides news diseminated on the Dow Jones newswire. Using a comprehensive sample of 294,977 firm-level news articles, we first conduct an event study of the relationship between financial news releases and the liquidity in the CDS market. Our univariate analysis shows that the bid-ask spread is higher, the number of pricing quotes is larger and the number of dealers is greater on news days than on days without news. These findings are consistent with predictions from Kim and Verrecchia (1994) that news release creates temporary information asymmetry, leading to less liquidity but higher trading volume. To formally test the predictions, we regress the changes in liquidity measures on a news dummy variable that equals to one if there is at least one news story

\footnotetext{
${ }^{1}$ As documented in Chen et al. (2011), major CDS market investors includes hedge funds, banks, insurance company, financial companies and asset managers.
} 
for a firm on a day and 0 otherwise. Consistent with the predictions, the coefficient of the dummy variable is estimated to be positive and statistically significant for all liquidity measures.

To provide support for our main results, we conduct several additional tests. We use earnings-related news to investigate how the arrival of earnings news affects CDS liquidity. Consistent with the finding in Kim and Verrecchia (1994), the result suggests that earningsrelated news has a strong effect on CDS liquidity. Then, we examine news associated with credit rating which can be easily interpreted by investors. The result shows that credit-rating-related news has no significant effect on CDS liquidity. Also consistent with Kim and Verrecchia (1994), these results suggest that simple and clear news does not increase information asymmetry at the time of release, and difficult-to-interpret news creates significant information asymmetry at the time of release.

We further investigate whether and how public financial news affects liquidity before and after news releases. Our hypothesis implies that the bid-ask spread increases when new information comes in. Since there is no new information release before the news releases, the bid-ask spread before news releases should keep the same holding other factors constant. Consistent with this expectation, we find that the bid-ask spread does not increase and even declines slightly several days prior to the news release. The bid-ask spread continues to increase for three days after news releases and reverts to normal levels afterward. There are some other interesting patterns. We find that the number of pricing quotes provided by dealers increases several days before news release and reverts to the normal level several days after news release, probably because traders execute more trades in anticipation of news releases. The number of dealers has a similar pattern that it increases in the run-up to the news arrival and then reverts to the normal level several days after. 
To check the robustness of our main results, we perform a battery of subsample analyses. First, we divide observations with at least one news story into two groups: the group with positive news sentiment and the other with negative news sentiment. We show that CDS liquidity measures are more responsive to news with negative sentiment. Second, we divide the sample into two groups: one with "hard" news (i.e. news related to firm's fundamentals) and the other with "soft" news, and observe liquidity significantly responds to the "hard" news. Third, we investigate the response of liquidity to scheduled and unscheduled news. The results reveal that CDS liquidity significantly and positively respond to unscheduled news. Fourth, we find that the responses of the liquidity measures to news are more pronounced for small firms. These findings suggest that the effects of financial news on liquidity are stronger for negative, fundamental, and unscheduled news and among firms with higher information asymmetry.

Our findings provide evidence that the information environment of the CDS market is close to the one described in Kim and Verrecchia (1994). That is, market participants in the CDS market are heterogeneous in the ability to process information. When public information is released, some market participants process public information into private and diverse information. This informed judgement generates information asymmetry between traders and dealers and leads to a temporary decrease in market liquidity.

The rest of the paper is organized as follows. We discuss the related literature and develop hypotheses in Section 2. Section 3 describes the construction of the data, variables and the methodology. We present the empirical results in Section 4. Section 5 concludes the paper.

\section{Literature review and hypothesis development}

In this section, we discuss the relevant literature and highlight our contributions to the 
literature in Sections 2.1 and 2.2. Section 2.3 develops the hypotheses for our empirical tests based on the insights gained from the literature review.

\subsection{Literature review on news release and market liquidity}

In this paper, we provide empirical evidence that is consistent with predictions in the theoretical literature. Kim and Verrecchia $(1991,1994)$ theoretically show that if traders have different abitlities to process public information, news releases (e.g., earnings announcemnets) lead to more information asymmetry, higher bid-ask spreads, and higher trading volume. This is because the announcemnts provide information that allows certain market participants to make superior judgments about a firm's performance than other market participants. Kim and Verrecchia (1997) study a model of rational trade with both private information gathered prior to a public disclosure (pre-announcement) and priviate information useful in conjunction with the disclosure (event-period). Their model shows that pre-announcement information leads to a positive association between trading volume and the absolute price change at the announcment.

Our paper contributes to the literature on the effects of public disclosure on liquidity. Mitchell and Mulherin (1994) and Berry and Howe (1994) find a significantly positive association between market trading volume and public information measured as the number of daily Dow Jones announcements and the number of news released by Reuter's News Service, respectively. Recent empirical studies investigate the impact of news releases on liquidity in equity markets. For example, Engelberg et al. (2012) find a sharp increase in bid-ask spreads for U.S. stocks on days with news from the Dow Jones archive. Storkenmaier et al. (2012) examine messages from Thomson Reuters newswire for FTSE 100 constituents traded on the London Stock Exchange (LSE) and Chi-X, and document that trading activity increases strongly on news release days. Neuhierl et al. (2013) study various types of press releases issued via major 
newswire services and find that bid-ask spreads decrease over the five-day following most categories of press releases. Bushee et al. (2010) show that the greater number of press sources during the earnings announcement period is associated with reduced bid-ask spreads and greater depth for a sample of mid-sized NASDAQ firms, suggesting improvement in information asymmetry. Using a large set of news data, we show that releases of public financial news affect liquidity in the CDS market.

Our study also contributes to the literature on the determinants of CDS liquidity. Understanding CDS liquidity is important since it affects CDS prices (Bongaerts et al., 2011; Lee et al., 2016, 2018), the comovement of CDS spreads (Anderson, 2017), CDS-bond basis (Nashikkar et al., 2011), pricing discrepancies across equity and CDS markets (Kapadia and $\mathrm{Pu}$, 2012), equity market quality (Boehmer et al., 2015), corporate capital structures (Saretto and Tookes, 2013), corporate innovation (Chang et al., 2019), and firm value (Narayanan and Uzmanoglu, 2018). Prior studies identify several determinants of CDS liquidity. Qiu and Yu (2012) use the number of quote providers as a measure of CDS market depth and show that large firms and firms that near the investment-grade/speculative-grade boundary tend to be the most liquid. Meng and ap Gwilym (2008) find CDS spread volatility, issuer credit rating, larger transaction size, and for the years 2004 and 2005, etc are all determine the CDS liquidity. We provide evidence that news releases affect CDS liquidity.

Finally, our paper is broadly related to the literature on the effects of media on financial markets. Early studies find that news affects stock pricing (e.g., Goh and Ederington, 1993; Tetlock, 2007; Fang and Peress, 2009; Birz and Lott, 2011; Aman, 2013), stock trading (Tetlock, 2007; Engelberg and Parsons, 2011), corporate bond liquidity (Jiang and Sun, 2015), bond pricing (Caporale et al., 2018), executive compensation (Kuhnen and Niessen, 2012), rating 
agencies' monitor (Bonsall IV et al., 2018), voting behavior (DellaVigna and Kaplan, 2007), CDS prices (Callen, Livant, and Segal, 2009; Shivakumar, Urcan, Vasvari, and Zhang, 2011; Kim, Shroff, Vyas, and Wittenbergmoerman, 2017), among others. Our results shed light on the effects of news releases on CDS liquidity, showing that news releases temporarily increase bidask spreads and, at the same time, increases liquidity demand from investors and liquidity provision by dealers in the CDS market.

\subsection{CDS market structure}

The CDS market is an opaque OTC market. Dealers provide liquidity to customers by holding a large inventory of CDS contracts. As illustrated in Figure 1, before entering into CDS transactions, customers send requests for pricing quotes to dealers who respond to customers' requests by providing bid and ask quotes. Chen et al. (2011) find evidence that dealers have to hedge large CDS positions with customers over a long time horizon. Eisfeldt et al. (2018) document that the CDS market consists of a small number of core dealers and a large number of peripheral customers. It has been documented that the CDS market leads both stock and bond markets in terms of information flow (e.g., Blanco et al., 2005; Acharya and Johnson, 2007; Lee et al., 2018). These findings suggest that CDS dealers are vulnerable to informed trading.

Acharya and Johnson (2007) document insider trading in the CDS market. They find that insider trading is stronger for firms with larger number of banking relationships. Qiu and $\mathrm{Yu}$ (2012) find that market depth is larger for firms with larger number of banking relationships. These findings suggest that non-public information motivates insider trading and liquidity provision. Our paper contributes to this literature by showing that public information may create temporary information asymmetry at the time of new releases.

\subsection{Empirical hypotheses}


Kim and Verrecchia (1994) contend that traders have heterogenous abitlity to process public information. Public news releases, such as earnings announcemnets, may lead to more short-term information asymmetry and thus higher bid-ask spreads, if the announcemnts provide information that allows certain market participants to make superior judgments about a firm's performance than other participants. Therefore, we test the following hypothesis:

\section{Hypothesis 1: The bid-ask spread increases at the time of public news releases.}

Kim and Verrecchia $(1991,1994)$ predict that trading volume can increase at the time of news releases as a result of heterogenous beliefs among traders. Since the CDS market is an OTC market, traders need to obtain pricing quotes from dealers before entering into transactions. Therefore, the number of pricing quotes can be a reasonable proxy for CDS trading volume. This implies that the number of pricing quotes should increase at the time of news releases. Hence, we test the following hypothesis:

\section{Hypothesis 2: The number of pricing quotes increases at the time of public news} releases.

One unique feature of our CDS data is the number of dealers. This allows us to test how the participation of dealers changes around news releases. As stated in Hypothesis 2, Kim and Verrecchia (1994) argue that informed trading drives up trading volume around news releases. Qiu and Yu (2012) show that the number of CDS dealers is greater for firms with higher degree of informed trading. Therefore, to meet the increased aggregate demand of liquidity, the number of dealers should also increase around news releases. We formalize our prediction as follows:

Hypothesis 3: The number of dealers increases at the time of public news releases. 


\section{Data and variable construction}

We start this section by describing how to obtain our sample and construct variables for the empirical analyses in Section 3.1. Then, we provide summary statistics on variables in Section 3.2 .

\subsection{Data and main variables}

The data for our empirical analyses are obtained from multiple sources. To measure CDS liquidity, we follow Loon and Zhong (2014) to retrieve daily bid-ask spread, quotes count, and dealers count for single-name CDS contracts on U.S. individual reference entities spanning the period from April 2010 to September 2016 from Markit Group Limited. ${ }^{2}$ We focus on contracts with five-year maturity since they are the mostly liquid contracts. Bid-ask spread is the difference between bid quotes and ask quotes for five-year CDS contracts of a given reference entity, expressed in basis points (bps). Quotes count is the daily number of unique quotes for a given reference entity. Dealers count is the daily number of distinct CDS dealers providing quotes for a given reference entity. Dealers count and Bid-ask spread are proxies for CDS liquidity provision while Quotes count is a proxy for CDS liquidity demand. We winsorize CDS liquidity measures at the top and bottom $1 \%$ to mitigate effects of outliers.

We extract and count a comprehensive range of firm-specific news events disseminated via Dow Jones Newswires from RavenPack News Analytics, which is widely used in recent empirical studies (see, e.g., Ben-Rephael et al., 2017; Bonsall IV et al., 2018; Dai et al., 2015; Drake et al., 2014; Drake et al., 2016; Twedt, 2016). For entities discussed in each news story, RavenPack assigns a relevance score ranging between 0 and 100 , reflecting to what extent the firm is closely related to the story. Following previous studies (Dai et al., 2015; Dang et al., 2015;

\footnotetext{
${ }^{2}$ This selection of time period reflects the availability of CDS liquidity data from Markit.
} 
deHaan et al., 2015; Gao et al., 2018), we retain only most relevant articles with the relevance score of 100 .

RavenPack also classifies stories based on their category information. ${ }^{3}$ To study news stories that convey material information about the firm rather than general market movements, we further eliminate news groups associated with trading or prices (technical analysis signals, stock price movements, and order imbalance reports) as in Gao et al. (2018) and Weller (2018). Table A of the Appendix provides a snapshot of common kinds of stories covered in our sample. We construct our primary variable of interest Ln(\#news) as the natural logarithm of one plus the total number of news events for a firm on a given date. By construction, this variable is zero if there is no firm-specific news event on a given date.

In our subsample analyses, we broadly split news into two types according to their theme: hard news and soft news as in Wang et al. (2017). Hard news, which comprises four news groups, "revenues", "earnings", "analyst-ratings", and "credit-ratings", is set to more closely reflect firms' fundamentals than soft news, which is made up of the remaining news groups, such as "insider-trading", "marketing", and etc. We also employ the event sentiment score (ESS) created by RavenPack, which has been widely utilized in recent empirical studies (see, e.g., Dang et al., 2015; Akbas et al., 2016; Gao et al., 2018). ESS reflects both the direction and the strength of the sentiment embedded in underlying articles by systematically matching the story on training sets typically recognized by financial experts as having a short-term favorable or unfavorable economic impact. ESS ranges from 0 (most negative tone) to 100 (most positive tone), with a score of 50 coincides to a neutral sentiment. RavenPack also provides a code for us to identify and count stories on unscheduled events separately from a firm's news coverage based on

\footnotetext{
${ }^{3}$ RavenPack generates the four-level event taxonomy to every news item: topic (highest level), group, type, and category (lowest level). For more details, see "A Guide to Trading and Investment Applications Using News Analytics", available at https://www.ravenpack.com/.
} 
scheduled activities.

To construct control variables, we retrieve reference entities' assets and liabilities from the Compustat, stock returns and trading volume from the Center for Research in Security Prices (CRSP). We define $\operatorname{Ln}($ size) as the natural logarithm of total assets. Leverage is computed as the total debt divided by total assets. Stock volatility is defined as the two-week rolling standard deviation of stock returns. $\operatorname{Ln}($ stock volume) is equal to the natural logarithm of shares traded on a given day. As a control of overall market movement, we obtain the daily closing level of S\&P 500 implied volatility index (VIX) from the Chicago Board Options Exchange (CBOE). We also extract the daily TED spread from the Federal Reserve Bank of St. Louis, which is calculated as the three-month uncollateralized London Interbank Offered Rate (LIBOR) minus the threemonth Treasury bill yield (in \%). After merging all data sets, we obtain a final sample of 462,832 daily observations on 397 U.S. firms.

\subsection{Descriptive statistics}

Table 1 presents summary statistics of the variables in our sample. The mean and median of bid-ask spreads are 16.01 and $10 \mathrm{bps}$, respectively. On average, there is 46.11 quotes per day for a firm (median of 39). The mean (median) number of dealers providing quotes for firms is 6.50 (7). These liquidity measures also have considerable variations in our sample. Ln(\#news) has a mean of 0.25 and a median of 0 . The mean (median) for $\operatorname{Ln}($ size) is 9.89 (9.78). For Leverage, the mean and median are 0.69 and 0.66 , respectively. The Stock volatility has a mean of 0.017 and a median of 0.014 . The average and median of Ln(stock volume) are 14.74 and 14.80 , respectively. VIX has a mean of 18.21 and a median of 16.48 , and the mean and median of TED spread are 0.27 and 0.23 , respectively.

$<$ Table 1> 


\section{Effects of financial news on liquidity}

In this section, we investigate the effects of financial news on liquidity in the CDS market. A univariate analysis is described in Section 4.1. We then examine the relation between news releases and the bid-ask spread, the number of pricing quotes, and the number of dealers in Section 4.2. We analyze two special types of news in Section 4.3 and the anticipation and reversal effect in Section 4.4. Finally, a series of subsample analyses are conducted in Section 4.5 .

\subsection{Univariate analysis}

Our investigation begins with a univariate analysis of news effects. Specifically, we divide our sample into two subsamples: observations with at least one news story and those without any news story. Then we compare the mean values of the three liquidity measures for the two subsamples. The results are reported in Table 2. The mean values of all three liquidity measures for observations with at least one news story in column (2) are larger than those for observations without news in column (1). For example, the average change in bid-ask spreads is 0.014 for the subsample with news and 0.002 for the subsample without news, suggesting that the bid-ask spread increases at the time of news releases. Column (3) shows that t-test for the difference in

means is statistically significant for all three liquidity measures. These results provide preliminary evidence that support our hypotheses.

$<$ Table 2>

\subsection{Effects of news releases on liquidity}




\subsubsection{Bid-ask spreads}

To test Hypothesis 1 that the bid-ask spread increases at the time of public news releases, we first examine the change in bid-ask spreads on news dates. We define a dummy variable $N e w s_{i, t}$ which is equal to one if there is at least one news story for the firm $i$ on date $t$, and 0 otherwise. To examine the impact of news releases on CDS liquidity, we estimate the following model:

$$
Y_{i, t}=\beta \cdot N e w s_{i, t}+\gamma \cdot X_{i, t}+\mu_{t}+\varphi_{i}+\epsilon_{i, t}
$$

where $Y_{i, t}$ refers to the change in one of the three CDS liquidity measures: Bid-ask spread, Dealers count, or Quotes count for firm $i$ at date $t, X_{i, t}$ represents a vector of firm-specific control variables including $L n($ size), Leverage, Stock volatility, Ln(stock volume), VIX, and TED spread, $\mu_{t}$ captures time (year-month and day-of-the-week) fixed effects, $\varphi_{i}$ represents firm fixed effects, and $\epsilon_{i, t}$ is the error term of the regression.

We also consider whether the effect of news releases on liquidity depends on news coverage. We define Ln(\#news) as the natural logarithm of the number of daily news articles plus one and estimate the following model:

$$
Y_{i, t}=\beta \cdot \operatorname{Ln}(\# n e w s)_{i, t}+\gamma \cdot X_{i, t}+\mu_{t}+\varphi_{i}+\epsilon_{i, t}
$$

Table 3 reports the regression results. In column (1), we include only the news dummy variable without any control variables. The estimate of News is 0.020 and statistically significant $(t=4.24)$. In column (2), we include control variables as specified in Equation (1) and the estimate of News becomes 0.017 and is still significant ( $t=3.44)$. Consistent with Hypothesis 1 , these results suggest that dealers increase the bid-ask spread on news dates in response to heightened information asymmetry. Second, we further examine whether the bid-ask spread is higher when the number of news counts is higher. To do so, we include the natural logarithm of the number of news counts plus one in the regressions as described in Equation (2). Columns (3) 
and (4) show that the regression results are similar to the results in columns (1) and (2). For example, in column (4), the estimate of Ln(\#news) is 0.018 and highly significant ( $t=4.14)$, indicating that the change in the bid-ask spread is positively associated with the number of news events.

In summary, these results provide support to Hypothesis 1 that the bid-ask spread increases at the time of public news releases.

$<$ Table 3>

\subsubsection{Number of pricing quotes}

The analysis in the prior section shows the bid-ask spread increases when news arrives. In this section, we test Hypothesis 2 that the number of pricing quotes, which is a proxy for CDS trading volume, increases at the time of public news releases. The number of pricing quotes represents the demand-side liquidity. We first regress the change in the number of quotes on the dummy variable News using Equation (1) and present the results in columns (1) and (2) of Table 4. The estimate of News is positive and highly significant, consistent with our hypothesis. Then, we estimate Equation (2) and present the results in columns (3) and (4). The estimate of Ln(\#news) is also positive and highly significant, indicating that CDS trading volume is positively associated with the number of news counts.

$<$ Table 4>

\subsubsection{Number of dealers}

One unique feature of our CDS data is the number of dealers. There is little research in the literature on how news releases affect liquidity provision by dealers. Hypothesis 3 predicts that the number of dealers increases at the time of public news releases. To test the hypothesis, we regress the change in the number of dealers on news dates on the dummy variable News using 
Equation (1). Table 5 reports the regression results. Consistent with our hypothesis 3, columns (1) and (2) show that more dealers are present in the CDS market on news dates. This result, together with those in Table 3, suggests that dealers increase the bid-ask spread while they provide more liquidity on news dates. Columns (3) and (4) show that the change in the number of dealers is also positively related to the number of news events.

$<$ Table 5>

\subsection{Earnings announcement and credit rating}

In this section, we conduct additional tests to provide support for our main results. Kim and Verrecchia (1994) suggest that the precision of public information affects the impact of public disclosure on liquidity. If a type of information disclosure is difficult to interpret (e.g., earnings announcements), it can create strong information asymmetry. If a type of information disclosure is simple and easy to interpret (e.g., credit rating changes), it will not create strong information asymmetry and thus its effect on liquidity could be insignificant. To test this prediction, we first focus on news related to earnings and investigate whether the arrival of earnings news affects CDS liquidity. Then, we concentrate on news associated with credit rating, and test if such kinds of news have diverse influence on CDS liquidity.

To test the effect of earnings announcements on CDS liquidity, we construct a dummy variable News which is one if there is earning-related news on date $t$, and 0 otherwise. Columns (1) and (2) of Table 6 present the regression results from Equation (1). The estimate of News is positive and highly significant. In particular, the magnitude of News is 0.076 in column (2), which is about four times of the estimate of News based on all news types (column (2) of Table 3). Consistent with Kim and Verrecchia (1994), this result suggests that earnings-related news decreases CDS liquidity at the time of release. 
Credit ratings are issued by rating agencies to help investors to assess credit quality of firms. Therefore, the information of credit rating news is less likely to create superior judgements for some traders. We expect no significant changes in bid-ask spreads at the time of credit rating news releases. To examine the impact of credit rating news on CDS liquidity, we set a dummy variable News which is 1 if there is credit-rating-related news on date $t$, and 0 otherwise. Columns (3) and (4) of Table 6 report the results estimating from Equation (1). Consistent with our expectation, columns (3) and (4) show that the impact of credit-rating-related news on the change in bid-ask spreads is statistically insignificant.

In summary, these results provide support to our main results by showing that news releases that are difficult to interpret lead to more information asymmetry and thus higher bid-ask spreads. $<$ Table 6>

\subsection{Pre- and post-release drift}

In this section, we examine changes in liquidity before and after the arrival of news. Following prior studies (e.g., Liebmann et al., 2016), we consider five periods around news release dates: five and three days preceding the release date $([-5,-1],[-3,-1])$, on the release date [0], and five and three days following the release date $([1,5],[1,3]) .{ }^{4}$ We examine changes in liquidity measures in these five periods using the regression specification in Equation (1) with dependent variable $Y_{i, t}$ replaced by changes in liquidity measures over the short interval from day $t+x$ through day $t+y$ for a given firm $i$, denoted as $Y_{i, t}[x, y]$.

The results of estimating Equation (1) are reported in Table 7. Panel A reports the regression results for the changes in bid-ask spreads in the five periods. Columns (1) and (2) show that the bid-ask spread does not increase in the period of five and three days before news release. This is

\footnotetext{
${ }^{4}$ We set news release dates as day 0 .
} 
consistent with the prediction in Kim and Verrecchia (1994). Column (3) shows a significant increase in the bid-ask spread at the time of news releases. Columns (4) and (5) suggest that the bid-ask spread continues to increase in the period of three days after news release, and reverts to the normal level in the period of five days after news release. These results indicate that CDS dealers do not increase the bid-ask spread until news release days, and revert it back to the normal level in several days after the news release. The top plot in Figure 2 shows the cumulative change in bid-ask spreads over the eleven-day window around news releases.

Panel B reports the regression results for the changes in the number of quotes in the five periods around news release. Columns (1) and (2) show that the number of quotes increases in the period of five and three days before news release. Column (3) shows a significant increase in the number of quotes at the time of news release. Columns (4) and (5) indicate that the number of quotes decreases in the period of three and five days after news release. Together with the results in Table 4, these results suggest that the number of quotes increases several days before and on news release dates, and reverts to the normal level in several days after the news release. The middle plot in Figure 2 depicts the cumulative change in the number of quotes over the eleven-day window around news releases.

Panel $\mathrm{C}$ shows the change in dealer count in the five periods around news release. The estimate of News is positive and significant in the five and three days preceding the news release date (columns (1) and (2)), suggesting that dealers increase liquidity provision several days before news release dates. Column (3) shows a significant increase in the number of dealers at the time of news release. Columns (4) and (5) show negative and significant estimates of News in the five and three days following the news release date. The estimate of News for the five days post-release period is -0.056 , whose magnitude is roughly equal to the sum of the estimate 
of News over five days preceding (0.039) and the estimate of News on news release dates $(0.11)$. This suggests that the liquidity provided by dealers reverts to the normal level several days after news release. The bottom plot in Figure 2 demonstrates the cumulative change in the number of dealers over the eleven-day window around news releases.

$<$ Table 7>

\subsection{Subsample analysis}

To further understand the relation between news releases and liquidity, we conduct a battery of subsample analyses. We first investigate the effect of news sentiment on liquidity. We divide the sample by news sentiment into two groups: one with positive sentiment $(\mathrm{ESS}>50)$ and the other with negative sentiment $(\mathrm{ESS}<50)$. For each group, we regress the liquidity measures employing Equation (2). The results are reported in Panel A of Table 8. For the negative sentiment group, the estimate of Ln(\#news) is positive and significant for all liquidity measures (columns (1), (3), and (5)). The estimate of Ln(\#news) for the positive sentiment group is positive and significant for dealers count and the number of quotes (columns (4) and (6)), and insignificant for the bid-ask spread (column (2)). These results suggest that the effect of financial news on liquidity is stronger for negative news. This is expected because credit investors are more concerned with negative news.

Second, we divide the sample into two groups following Wang et al. (2017): one with hard news and the other with soft news. Hard news, which consists of four news groups, "revenues", "earnings", "analyst-ratings", and "credit-ratings", is set to more closely reflect firms' fundamentals than soft news, which comprises the remaining news groups, such as "insidertrading", "marketing", and so on. For each group, we run Equation (2) and report the results in Panel B of Table 8. The estimate of Ln(\#news) is positive and significant for the hard news group 
(columns (1), (3) and (5)), and insignificant for the soft news group in terms of bid-ask spread and the number of dealers (columns (2) and (6)). These results suggest that the effect of financial news on liquidity is mainly driven by news more relevant for fundamental information.

Third, we divide the sample into two groups: one with scheduled news and the other with unscheduled news. For each group, we run Equation (2) and report the results in Panel C of Table 8. The estimate of Ln(\#news) is positive and significant for the unscheduled group (columns (1), (3) and (5)), and insignificant for the scheduled news group for the bid-ask spread and dealers count (columns (2) and (6)). In column (4), the estimate of Ln(\#news) for the scheduled news group is also positive and significant for the number of quotes.

Fourth, Stiglitz and Weiss (1981) demonstrate that small firms have higher information frictions. We split the sample into two groups: one with total assets below the sample median and the other with total assets larger than the sample median. For each group, we run Equation (2) and report the results in Panel D of Table 8. The estimate of Ln(\#news) for the small firm group is positive and significant for all liquidity measures (columns (1), (3), and (5)). For the large firm group, the estimate of $L n(\# n e w s)$ is positive and significant for the number of quotes and dealers count (columns (4) and (6)), and insignificant for the bid-ask spread (column (2)). These results suggest that the effect of financial news on liquidity is stronger for firms with higher information asymmetry.

\section{<Table 8>}

Finally, we consider a type of news that could reduce information asymmetry at the time of releases. Analyst rating is a reinterpretation of public information and is very unlikely to create superior judgements among traders at the time of release (Livnat and Zhang, 2012; Rubin et al., 2017). We split the sample with analyst rating related news into three groups: analyst rating 
downgrade, neutral, and upgrade. For each group, we run Equation (2) and report the results in Table 9. Columns (1) to (4) show that the effect of news with analyst rating downgrade and neutral on liquidity is insignificant. Interestingly, columns (5) and (6) indicates that news with analyst rating upgrade actually reduces information asymmetry, which is consistent with the diverse impact of public disclosures put forward by Kim and Verrecchia (1994).

<Table 9>

In summary, the subsample analyses provide additional support to our hypotheses, suggesting that the effects of financial news on liquidity is stronger for negative, hard, unscheduled news and firms with higher information asymmetry.

\section{Conclusions}

The effect of news coverage on market liquidity, especially for non-stock markets is far less investigated. Using a large set of news releases, we investigate the effect of news releases on CDS liquidity. We document that dealers temporarily increase bid-ask spreads on news release dates in response to higher information asymmetry. The number of dealers also increases on news days to accommodate higher liquidity demand.

Further, we investigate changes in liquidity before and after the arrival of news. We conclude that liquidity provided by dealers increases several days before news release and reverts to the normal level several days after news release. The number of quotes has an analogous pattern that increases before news arrival but reverts to the normal level in several days after. However, the bid-ask spread decreases significantly preceding the news release. It widens on and immediately following the news release day and reverses back after the news release. 
Finally, our additional tests provide more insights into how news coverage affects CDS liquidity. We show that CDS liquidity measures significantly react to news with strong positive or negative sentiment. The effect of news coverage on CDS liquidity is more pronounced among news that is related to firm's fundamentals and unscheduled news, and small firms.

Examining the relationship between news and CDS liquidity can help institutional investors to manage liquidity risk and investment decisions. Furthermore, such investigation can also extend our knowledge about institutional investors' behaviors. This is important as the responses of institutional investors might vary with individual investors as they might react quickly to major events. Finally, liquidity might interest to regulators as greater liquidity is beneficial to the economy. 


\section{Appendix}

\section{Table A: Summary statistics of news items}

This table presents RavenPack company news categories with observations more than $1 \%$ of all observations in our sample. The sample consists of observations on 397 U.S. firms from April 2010 to September 2016.

\begin{tabular}{llc}
\hline Group & Category & $\mathrm{N}$ \\
\hline acquisitions-mergers & acquisition-acquirer & 4,118 \\
analyst-ratings & analyst-ratings-change-negative & 3,709 \\
analyst-ratings & analyst-ratings-change-positive & 3,558 \\
credit & note-sale & 3,681 \\
credit-ratings & credit-rating-set & 5,537 \\
credit-ratings & credit-rating-affirmation & 4,312 \\
dividends & dividend & 4,773 \\
dividends & dividend-up & 2,992 \\
earnings & earnings-per-share-positive & 10,977 \\
earnings & earnings-up & 8,569 \\
earnings & earnings & 8,243 \\
earnings & earnings-positive & 6,628 \\
earnings & earnings-down & 5,369 \\
earnings & earnings-per-share-guidance & 3,866 \\
insider-trading & insider-sell & 22,054 \\
insider-trading & insider-sell-registration & 17,019 \\
insider-trading & insider-buy & 15,236 \\
insider-trading & insider-surrender & 13,333 \\
investor-relations & major-shareholders-disclosure & 4,613 \\
investor-relations & conference-call & 3,929 \\
labor-issues & executive-appointment & 13,210 \\
labor-issues & executive-resignation & 3,104 \\
partnerships & partnership & 4,109 \\
products-services & business-contract & 10,215 \\
products-services & product-release & 9,782 \\
revenues & revenues & 13,710 \\
revenues & revenue-up & 4,057 \\
\hline
\end{tabular}




\section{References}

Acharya, V., and Johnson, T., 2007. Insider trading in credit derivatives. Journal of Financial Economics 84, 110-141.

Akbas, F., Boehmer, E., Erturk, B., and Sorescu, S. 2016. Short interest, returns, and unfavorable fundamental information. Financial Management, 46(2): 455-486.

Aman, H. 2013. An analysis of the impact of media coverage on stock price crashes and jumps: Evidence from Japan. Pacific-Basin Finance Journal, 24: 22-38.

Anderson, M. 2017. What drives the commonality between credit default swap spread changes? Journal of Financial and Quantitative Analysis, 52(1): 243-275.

Ben-Rephael, A., Da, Z., and Israelsen, R. D. 2017. It depends on where you search: Institutional investor attention and underreaction to news. Review of Financial Studies, 30(9): 30093047.

Berry, T. D., and Howe, K. M. 1994. Public information arrival. Journal of Finance, 49(4): 1331-1346.

Blanco, R., Brennan, S., and Marsh, I., 2005. An empirical analysis of the dynamic relationship between investment grade bonds and credit default swaps. Journal of Finance 60, 22552281.

Birz, G., and Lott, J. R. 2011. The effect of macroeconomic news on stock returns: New evidence from newspaper coverage. Journal of Banking \& Finance, 35(11): 2791-2800.

Boehmer, E., Chava, S., and Tookes, H. E. 2015. Related securities and equity market quality: The case of CDS. Journal of Financial and Quantitative Analysis, 50(3): 509-541.

Bongaerts, D., De Jong, F., and Driessen, J. 2011. Derivative pricing with liquidity risk: Theory and evidence from the credit default swap market. Journal of Finance, 66(1): 203-240.

Bonsall IV, S.B., Green, J.R., Muller III, K.A., 2018. Are credit ratings more rigorous for widely covered firms? Accounting Review, 93, 61-94.

Bushee, B. J., Core, J. E., Guay, W., and Hamm, S. J. W. 2010. The role of the business press as an information intermediary. Journal of Accounting Research, 48(1): 1-19.

Callen, J.L., Livant, J., and Segal, D. 2009. The impact of earnings on the pricing of credit default swaps. The Accounting Review, 84(5), 1363-1394.

Caporale, G. M., Spagnolo, F., and Spagnolo, N. 2018. Macro news and bond yield spreads in the euro area. European Journal of Finance, 24(2): 114-134.

Chang, X., Chen, Y., Wang, S. Q., Zhang, K., and Zhang, W. 2019. Credit default swaps and corporate innovation. Journal of Financial Economics 134(2): 474-500. 
Chen, K., Fleming, M. J., Jackson, J. P., Li, A., and Sarkar, A. 2011. An analysis of CDS transactions: Implications for public reporting, Federal Reserve Bank of New York Staff Reports.

Dai, L., Parwada, J. T., and Zhang, B. 2015. The governance effect of the media's news dissemination role: Evidence from insider trading. Journal of Accounting Research, 53(2): 331-366.

Dang, T. L., Moshirian, F., and Zhang, B. 2015. Commonality in news around the world. Journal of Financial Economics, 116(1): 82-110.

deHaan, E., Shevlin, T., and Thornock, J. 2015. Market (in)attention and the strategic scheduling and timing of earnings announcements. Journal of Accounting and Economics, 60(1): 3655 .

DellaVigna, S., and Kaplan, E. 2007. The Fox News effect: Media bias and voting. Quarterly Journal of Economics, 122(3): 1187-1234.

Diamond, D. W., and Verrecchia, R. E. 1991. Disclosure, liquidity, and the cost of capital. Journal of Finance, 46(4): 1325-1359.

Drake, M. S., Guest, N. M., and Twedt, B. J. 2014. The media and mispricing: The role of the business press in the pricing of accounting information. Accounting Review, 89(5): 16731701.

Drake, M. S., Jennings, J., Roulstone, D. T., and Thornock, J. R. 2016. The comovement of investor attention. Management Science, 63(9): 2847-2867.

Eisfeldt, A. L., Herskovic, B., Rajan, S., and Siriwardane, E. 2018. OTC intermediaries. Working paper.

Engelberg, J. E., and Parsons, C. A. 2011. The causal impact of media in financial markets. Journal of Finance, 66(1): 67-97.

Engelberg, J. E., Reed, A. V., and Ringgenberg, M. C. 2012. How are shorts informed?: Short sellers, news, and information processing. Journal of Financial Economics, 105(2): 260278.

Fang, L., and Peress, J. 2009. Media coverage and the cross-section of stock returns. Journal of Finance, 64(5): 2023-2052.

Fang, L. H., Peress J., and Zheng L. 2014. Does media coverage of stocks affect mutual funds' trading and performance? Review of Financial Studies, 27 (12):3441-3466.

Gao, P., Parsons, C. A., and Shen, J. 2018. Global relation between financial distress and equity returns. Review of Financial Studies, 31(1): 239-277.

Goh, J. C., and Ederington, L. H. 1993. Is a bond rating downgrade bad news, good news, or no news for stockholders? Journal of Finance, 48(5): 2001-2008. 
Harris, M., and Raviv, A. 1993. Differences of opinion make a horse race. Review of Financial Studies 6:473-506.

Jiang, H., and Sun, Z. 2015. News and corporate bond liquidity. Working paper.

Kapadia, N., and $\mathrm{Pu}, \mathrm{X}$. 2012. Limited arbitrage between equity and credit markets. Journal of Financial Economics, 105(3): 542-564.

Kim, J. B., Shroff, P. K., Vyas, D., and Wittenbergmoerman, R. 2017. Credit default swaps and managers' voluntary disclosure. Journal of Accounting Research, 56(3), 953-988.

Kim, O., and Verrecchia, R. E. 1991. Trading volume and price reactions to public announcements. Journal of Accounting Research, 29(2): 302-321.

Kim, O., and Verrecchia, R. E. 1994. Market liquidity and volume around earnings announcements. Journal of Accounting and Economics, 17(1-2): 41-67.

Kim, O., and Verrecchia, R. E. 1997. Pre-announcement and event-period private information. Journal of Accounting and Economics, 24(3): 395-419.

Kuhnen, C. M., and Niessen, A. 2012. Public opinion and executive compensation. Management Science, 58(7): 1249-1272.

Lee, J., Naranjo, A., and Sirmans, S. 2016. Exodus from sovereign risk: Global asset and information networks in the pricing of corporate credit risk. Journal of Finance, 71(4): 1813-1856.

Lee, J., Naranjo, A., and Velioglu, G. 2018. When do CDS spreads lead? Rating events, private entities, and firm-specific information flows. Journal of Financial Economics, 130(3): 556-578.

Liebmann, M., Orlov, A. G., and Neumann, D. 2016. The tone of financial news and the perceptions of stock and CDS traders. International Review of Financial Analysis, 46: 159-175.

Liu, L. X., Sherman, A. E., and Zhang, Y. 2014. The long-run role of the media: Evidence from initial public offerings. Management Science, 60(8): 1945-1964.

Livnat, J., and Zhang, Y. 2012. Information interpretation or information discovery: Which role of analysts do investors value more? Review of Accounting Studies, 17(3): 612-641.

Loon, Y. C., and Zhong, Z. K. 2014. The impact of central clearing on counterparty risk, liquidity, and trading: Evidence from the credit default swap market. Journal of Financial Economics, 112(1): 91-115.

Meng, L., and Gwilym, O. A. 2008. The determinants of CDS bid-ask spreads. Journal of Derivatives, 16(1): 70-80.

Mitchell, M. L., and Mulherin, J. H. 1994. The impact of public information on the stock market. Journal of Finance, 49(3): 923-950. 
Narayanan, R., and Uzmanoglu, C. 2018. Credit default swaps and firm value. Journal of Financial and Quantitative Analysis, 53(3): 1227-1259.

Nashikkar, A., Subrahmanyam, M. G., and Mahanti, S. 2011. Liquidity and arbitrage in the market for credit risk. Journal of Financial and Quantitative Analysis, 46(3): 627-656.

Neuhierl, A., Scherbina, A., and Schlusche, B. 2013. Market reaction to corporate press releases. Journal of Financial and Quantitative Analysis, 48(4): 1207-1240.

Qiu, J., and Yu, F. 2012. Endogenous liquidity in credit derivatives. Journal of Financial Economics, 103(3): 611-631.

Rubin, A., Segal, B., and Segal, D. 2017. The interpretation of unanticipated news arrival and analysts' skill. Journal of Financial and Quantitative Analysis, 52(4): 1491-1518.

Saretto, A., and Tookes, H. E. 2013. Corporate leverage, debt maturity, and credit supply: The role of credit default swaps. Review of Financial Studies, 26(5): 1190-1247.

Shivakumar, L., Urcan, O., Vasvari, F. P., and Zhang, L. 2011. The debt market relevance of management earnings forecasts: Evidence from before and during the credit crisis. Review of Accounting Studies, 16(3), 464-486.

Stiglitz, J.E., Weiss, A., 1981. Credit rationing in markets with imperfect information. American Economic Review 71, 393-410.

Storkenmaier, A., Wagener, M., and Weinhardt, C. 2012. Public information in fragmented markets. Financial Markets and Portfolio Management, 26(2): 179-215.

Tetlock, P. C. 2007. Giving content to investor sentiment: The role of media in the stock market. Journal of Finance, 62(3): 1139-1168.

Tetlock, P. C. 2010. Does public financial news resolve asymmetric information? Review of Financial Studies, 23 (9):3520-3557.

Twedt, B. 2016. Spreading the word: Price discovery and newswire dissemination of management earnings guidance. Accounting Review, 91(1): 317-346.

Wang, Y., Zhang, B., and Zhu, X. 2017. The momentum of news. Working paper.

Weller, B. M. 2018. Does algorithmic trading reduce information acquisition? Review of Financial Studies, 31(6): 2184-2226. 


\section{Figure 1: CDS trading}

This plot illustrates a typical CDS trading process. CDS investors select multiple dealers and request quotes from them. Interested dealers send ask and bid prices back to the investors.

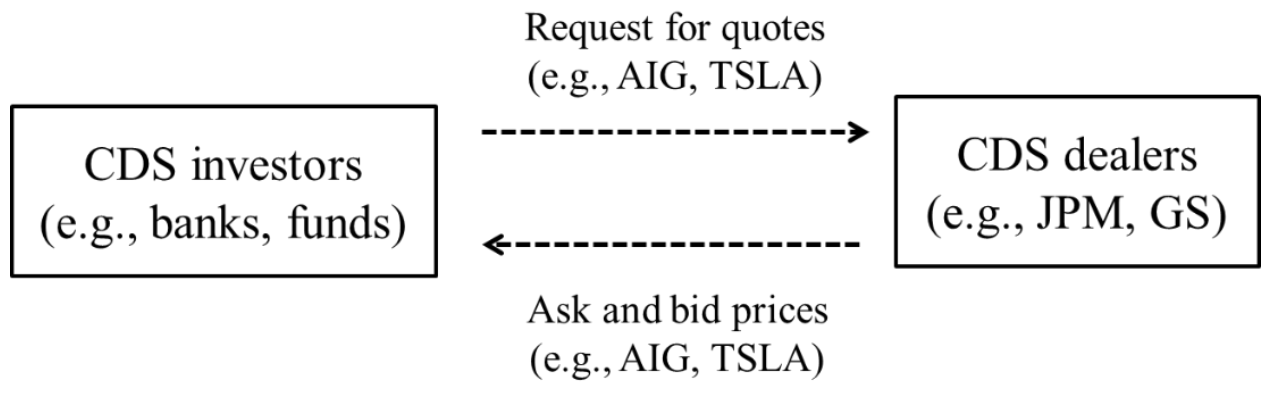




\section{Figure 2: CDS liquidity around the news release}

This figure plots the average cumulative change in three CDS liquidity measures (top: bid-ask spread; middle: number of quotes; bottom: number of dealers) from five-day before the news release to five-day after the news release along with confidence intervals at $10 \%$ level.
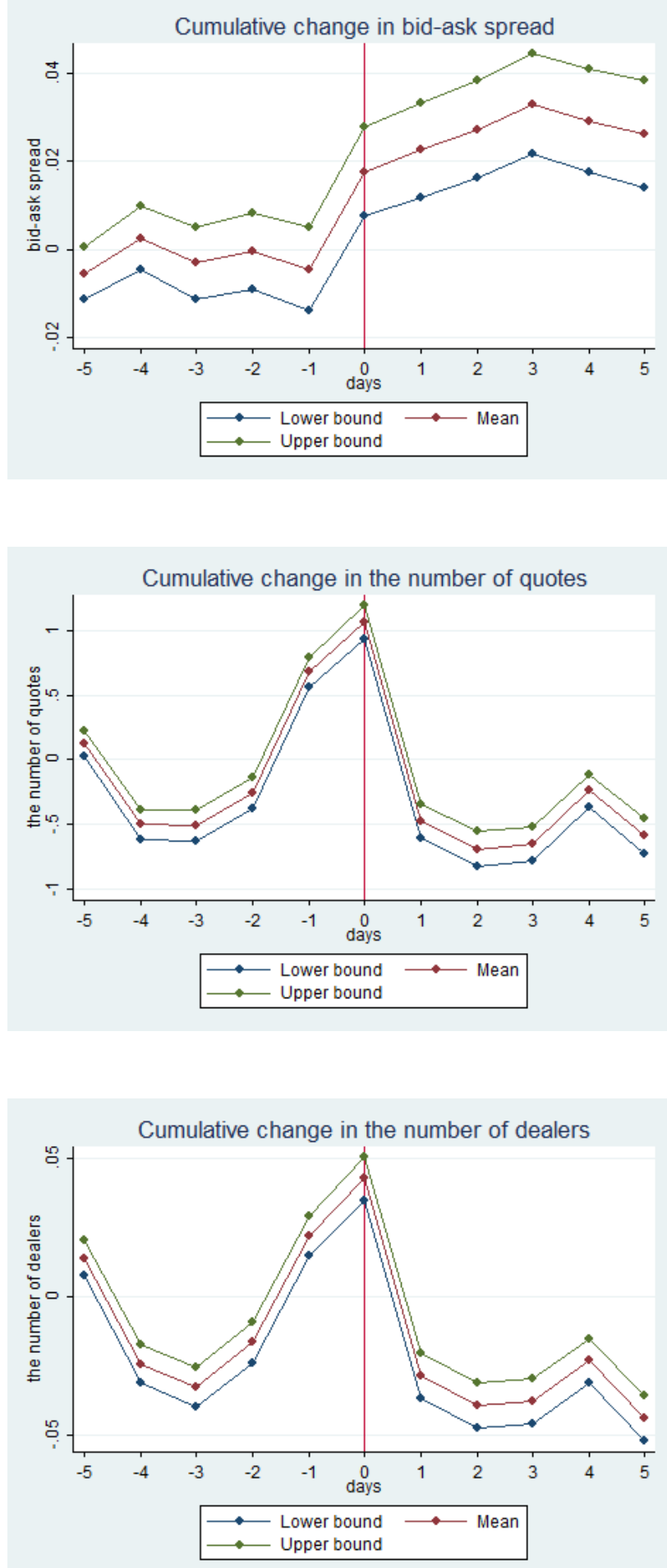


\section{Table 1: Summary statistics of main variables}

This table presents summary statistics of the main variables in our U.S. sample. Our sample consists of 462,832 daily observations of 397 U.S. firms over the period from April 2010 to September 2016. Bid-ask spread is the difference between bid spreads and ask spreads for fiveyear CDS contracts of a given reference entity, expressed in basis points. Quotes count is the daily number of unique quotes for a given reference entity across all tenors. Dealers count is the daily number of distinct CDS dealers quoting prices for a given reference entity across all tenors. Ln(\#news) refers the natural logarithm of one plus the total number of stories published on the Dow Jones newswire on a given day. $\operatorname{Ln}($ size $)$ is the logarithmic value of total assets. Leverage is the ratio of total debt to total assets. Stock volatility is defined as the two-week rolling standard deviation of stock returns. Ln(stock volume) is the natural logarithm of shares traded on a given day. VIX is the daily closing level of the Chicago Board Options Exchange (CBOE) S\&P 500 implied volatility index. TED spread is equal to the daily difference between the three-month uncollateralized London Interbank Offered Rate (LIBOR) and the three-month Treasury bill yield (in \%).

\begin{tabular}{lcccccc}
\hline Variables & Mean & Std. Dev. & 5th Pctl & Median & 95th Pctl & N \\
\hline Bid-ask spread & 16.011 & 135.549 & 4.750 & 10.000 & 35.780 & 461,928 \\
Quotes count & 46.106 & 35.615 & 6.000 & 39.000 & 108.000 & 462,832 \\
Dealers count & 6.497 & 2.716 & 2.000 & 7.000 & 11.000 & 462,832 \\
Ln(\#news) & 0.245 & 0.543 & 0.000 & 0.000 & 1.386 & 462,832 \\
Ln(size) & 9.892 & 1.316 & 7.843 & 9.782 & 12.200 & 414,575 \\
Leverage & 0.688 & 0.192 & 0.436 & 0.663 & 0.968 & 414,575 \\
Stock volatility & 0.017 & 0.012 & 0.006 & 0.014 & 0.037 & 417,745 \\
Ln(stock volume) & 14.744 & 1.394 & 12.919 & 14.803 & 16.734 & 417,229 \\
VIX & 18.210 & 6.082 & 12.190 & 16.480 & 32.000 & 461,561 \\
TED spread & 0.270 & 0.101 & 0.150 & 0.230 & 0.480 & 462,832 \\
\hline
\end{tabular}




\section{Table 2 Univariate analysis of news effect on CDS liquidity}

This table provides univariate analysis of the effect of financial news on CDS liquidity. Column (1) reports the summary statistics for observations without news. Column (2) reports the summary statistics of the changes in bid-ask spreads, the change in the number of pricing quotes and the change in the number of dealers for observations with at least one news story. The difference in means between the CDS liquidity for days without news (Column (1)) and those with news (Column (2)) is presented in Column (3). *,**, and *** indicate the difference in means between the groups is significant at the $10 \%, 5 \%$, and $1 \%$ levels, respectively.

\begin{tabular}{|c|c|c|c|c|c|c|c|}
\hline \multirow[t]{2}{*}{ Variables } & \multicolumn{3}{|c|}{ Observations without news (1) } & \multicolumn{3}{|c|}{ Observations with news (2) } & \multirow{2}{*}{$\begin{array}{l}\text { Test of mean diff. } \\
(3)=(2)-(1)\end{array}$} \\
\hline & Mean & Median & $\mathrm{N}$ & Mean & Median & $\mathrm{N}$ & \\
\hline$\Delta$ Bid-ask spread & 0.002 & 0.000 & 361,348 & 0.014 & 0.000 & 100,042 & $0.012 * *$ \\
\hline$\Delta$ Quotes count & -0.127 & -1.000 & 362,212 & 0.285 & 0.000 & 100,223 & $0.412 * * *$ \\
\hline$\Delta$ Dealers count & -0.004 & 0.000 & 362,212 & 0.016 & 0.000 & 100,223 & $0.019 * * *$ \\
\hline
\end{tabular}




\section{Table 3 Effect of public financial news on the bid-ask spread}

This table presents results from regressions that examine how news releases affect CDS liquidity provision. The dependent variable is the change in CDS bid-ask spreads of the reference entity $i$ on day $t$. News is a dummy variable that equals one if there is at least one news story on a given day, and 0 otherwise. Ln(\#news) is the log of one plus the total number of stories published on the Dow Jones newswire on a given day. The control variables are described in table 1 . The regressions include firm, year-month, and day-of-the-week fixed effects. Standard errors are clustered at the firm dimension and corrected for heteroskedasticity. t-statistics are reported in parentheses. *, **, and *** indicate significance at the $10 \%, 5 \%$, and $1 \%$ levels, respectively.

\begin{tabular}{|c|c|c|c|c|}
\hline & \multicolumn{4}{|c|}{ Dependent variable $=\Delta$ Bid-ask spread $[0]$} \\
\hline & $(1)$ & $(2)$ & (3) & $(4)$ \\
\hline News & $\begin{array}{c}0.020 * * * \\
(4.24)\end{array}$ & $\begin{array}{c}0.017 * * * \\
(3.44)\end{array}$ & & \\
\hline Ln(\#news) & & & $\begin{array}{c}0.021 * * * \\
(5.10)\end{array}$ & $\begin{array}{c}0.018 * * * \\
(4.14)\end{array}$ \\
\hline $\operatorname{Ln}(\operatorname{size})$ & & $\begin{array}{c}-0.025^{* *} \\
(-2.20)\end{array}$ & & $\begin{array}{c}-0.025^{* *} \\
(-2.17)\end{array}$ \\
\hline Leverage & & $\begin{array}{l}0.040 \\
(1.23)\end{array}$ & & $\begin{array}{l}0.040 \\
(1.23)\end{array}$ \\
\hline Stock volatility & & $\begin{array}{c}-2.633^{* * * *} \\
(-6.40)\end{array}$ & & $\begin{array}{c}-2.629 * * * \\
(-6.39)\end{array}$ \\
\hline Ln(stock volume $)$ & & $\begin{array}{c}0.044 * * * \\
(8.77)\end{array}$ & & $\begin{array}{c}0.042 * * * \\
(8.52)\end{array}$ \\
\hline$V I X$ & & $\begin{array}{c}0.030 * * * \\
(16.86)\end{array}$ & & $\begin{array}{c}0.031 * * * \\
(16.88)\end{array}$ \\
\hline TED spread & & $\begin{array}{c}-0.490 * * * \\
(-5.28)\end{array}$ & & $\begin{array}{c}-0.490 * * * \\
(-5.27)\end{array}$ \\
\hline Observations & 461,390 & 411,763 & 461,390 & 411,763 \\
\hline Adjusted R-squared & 0.003 & 0.006 & 0.003 & 0.006 \\
\hline Fixed effects & Yes & Yes & Yes & Yes \\
\hline Number of firms & 392 & 364 & 392 & 364 \\
\hline
\end{tabular}




\section{Table 4 Effect of public financial news on the number of quotes}

This table presents results from regressions that examine how news releases affect CDS liquidity demand. The dependent variable is the change in the number of pricing quotes for the reference entity $i$ on day $t$. News is a dummy variable that equals one if there is at least one news story on a given day, and 0 otherwise. Ln(\#news) is the log of one plus the total number of stories published on the Dow Jones newswire on a given day. The control variables are described in table 1. The regressions include firm, year-month, and day-of-the-week fixed effects. Standard errors are clustered at the firm dimension and corrected for heteroskedasticity. t-statistics are reported in parentheses. *, **, and *** indicate significance at the $10 \%, 5 \%$, and $1 \%$ levels, respectively.

\begin{tabular}{|c|c|c|c|c|}
\hline & \multicolumn{4}{|c|}{ Dependent variable $=\Delta$ Quotes count $[0]$} \\
\hline & $(1)$ & $(2)$ & $(3)$ & (4) \\
\hline News & $\begin{array}{c}0.487 * * * \\
(6.64)\end{array}$ & $\begin{array}{c}0.335 * * * \\
(4.57)\end{array}$ & & \\
\hline Ln(\#news) & & & $\begin{array}{c}0.802 * * * \\
(9.66)\end{array}$ & $\begin{array}{c}0.656^{* * * *} \\
(7.97)\end{array}$ \\
\hline Ln(size) & & $\begin{array}{c}-0.301 * * * \\
(-3.92)\end{array}$ & & $\begin{array}{c}-0.289 * * * * \\
(-4.00)\end{array}$ \\
\hline Leverage & & $\begin{array}{l}0.140 \\
(0.62)\end{array}$ & & $\begin{array}{l}0.160 \\
(0.75)\end{array}$ \\
\hline Stock volatility & & $\begin{array}{c}-22.928 * * * * \\
(-8.31)\end{array}$ & & $\begin{array}{c}-22.826 * * * \\
(-8.35)\end{array}$ \\
\hline Ln(stock volume) & & $\begin{array}{c}0.801 * * * \\
(10.88)\end{array}$ & & $\begin{array}{c}0.713 \text { *** } \\
(10.40)\end{array}$ \\
\hline$V I X$ & & $\begin{array}{c}0.082 * * * \\
(10.66)\end{array}$ & & $\begin{array}{c}0.085^{* * * *} \\
(11.12)\end{array}$ \\
\hline TED spread & & $\begin{array}{c}-10.250 * * * \\
(-16.31)\end{array}$ & & $\begin{array}{c}-10.180 * * * \\
(-16.23)\end{array}$ \\
\hline Observations & 462,435 & 412,521 & 462,435 & 412,521 \\
\hline Adjusted R-squared & 0.180 & 0.186 & 0.180 & 0.187 \\
\hline Fixed effects & Yes & Yes & Yes & Yes \\
\hline Number of firms & 392 & 364 & 392 & 364 \\
\hline
\end{tabular}




\section{Table 5 Effect of public financial news on the number of dealers}

This table presents results from panel regressions that examine how news releases affect CDS liquidity provision. The dependent variable is the change in number of dealers quoting for reference entity $i$ on day $t$. News is a dummy variable that equals one if there is at least one news story on a given day, and 0 otherwise. Ln(\#news) is the log of one plus the total number of stories published on the Dow Jones newswire on a given day. The control variables are described in table 1. The regressions include firm, year-month, and day-of-the-week fixed effects. Standard errors are clustered at the firm dimension and corrected for heteroskedasticity. t-statistics are reported in parentheses. $*, * *$, and $* * *$ indicate significance at the $10 \%, 5 \%$, and $1 \%$ levels, respectively.

\begin{tabular}{|c|c|c|c|c|}
\hline & \multicolumn{4}{|c|}{ Dependent variable $=\Delta$ Dealers count $[0]$} \\
\hline & (1) & (2) & (3) & (4) \\
\hline News & $\begin{array}{c}0.021 * * * \\
(5.34)\end{array}$ & $\begin{array}{c}0.011 * * * \\
(2.78)\end{array}$ & & \\
\hline Ln(\#news) & & & $\begin{array}{c}0.025^{* * *} * \\
(8.23)\end{array}$ & $\begin{array}{c}0.017 \text { *** } \\
(5.32)\end{array}$ \\
\hline $\operatorname{Ln}($ size $)$ & & $\begin{array}{c}-0.012 * * * \\
(-2.94)\end{array}$ & & $\begin{array}{c}-0.012 * * * \\
(-2.95)\end{array}$ \\
\hline Leverage & & $\begin{array}{c}0.017 * \\
(1.71)\end{array}$ & & $\begin{array}{c}0.018^{*} \\
(1.79)\end{array}$ \\
\hline Stock volatility & & $\begin{array}{c}-1.244 * * * \\
(-8.27)\end{array}$ & & $\begin{array}{c}-1.241 * * * \\
(-8.30)\end{array}$ \\
\hline Ln(stock volume $)$ & & $\begin{array}{c}0.041 * * * \\
(11.82)\end{array}$ & & $\begin{array}{c}0.039 * * * \\
(11.50)\end{array}$ \\
\hline$V I X$ & & $\begin{array}{c}0.009 * * * \\
(17.53)\end{array}$ & & $\begin{array}{c}0.009 * * * \\
(17.69)\end{array}$ \\
\hline TED spread & & $\begin{array}{c}-1.112 * * * \\
(-20.30)\end{array}$ & & $\begin{array}{c}-1.111 * * * \\
(-20.28)\end{array}$ \\
\hline Observations & 462,435 & 412,521 & 462,435 & 412,521 \\
\hline Adjusted R-squared & 0.119 & 0.122 & 0.119 & 0.122 \\
\hline Fixed effects & Yes & Yes & Yes & Yes \\
\hline Number of firms & 392 & 364 & 392 & 364 \\
\hline
\end{tabular}




\section{Table 6 Earnings and credit rating changes}

This table presents results from daily panel regressions that examine how the arrival of earnings, credit-rating and positive analyst-rating news affects CDS liquidity. The dependent variable is the change in bid-ask spread. In columns (1) and (2), News is a dummy variable that equals 1 if there is earnings news on a given day, and 0 otherwise. In columns (3) and (4), News is a dummy variable that equals 1 if there is credit-rating news on a given day, and 0 otherwise. The control variables are described in table 1 . The regressions include firm, year-month, and day-of-theweek fixed effects. Standard errors are clustered at the firm dimension and corrected for heteroskedasticity. t-statistics are reported in parentheses. ${ }^{*}, * *$, and $* * *$ indicate significance at the $10 \%, 5 \%$, and $1 \%$ levels, respectively.

\begin{tabular}{|c|c|c|c|c|}
\hline & \multicolumn{2}{|c|}{ Earnings } & \multicolumn{2}{|c|}{ Credit-rating } \\
\hline & (1) & (2) & (3) & (4) \\
\hline News & $\begin{array}{c}0.087 * * * \\
(5.44)\end{array}$ & $\begin{array}{c}0.076^{* * * *} \\
(4.61)\end{array}$ & $\begin{array}{l}0.020 \\
(1.05)\end{array}$ & $\begin{array}{l}0.024 \\
(1.19)\end{array}$ \\
\hline Controls & No & Yes & No & Yes \\
\hline Observations & 461,390 & 411,763 & 461,390 & 411,763 \\
\hline Adjusted R-squared & 0.003 & 0.006 & 0.003 & 0.006 \\
\hline Fixed effects & Yes & Yes & Yes & Yes \\
\hline Number of clusters & 392 & 364 & 392 & 364 \\
\hline
\end{tabular}




\section{Table 7 Pre- and post-release drift}

This table presents results from daily panel regressions that examine CDS liquidity before and after the arrival of news. The dependent variables are change in CDS liquidity (bid-ask spread in Panel A, the number of quotes in Panel B, and the number of dealers in Panel C) over days both preceding, on and following the current trading day $t$. News is a dummy variable that equals one if there is at least one news story on a given day, and 0 otherwise. The control variables are described in table 1. The regressions include firm, year-month, and day-of-the-week fixed effects. Standard errors are clustered at the firm dimension and corrected for heteroskedasticity. tstatistics are reported in parentheses. $*, * *$, and $* * *$ indicate significance at the $10 \%, 5 \%$, and $1 \%$ levels, respectively.

Panel A: Bid-ask spread

\begin{tabular}{|c|c|c|c|c|c|}
\hline & \multicolumn{5}{|c|}{ Dependent variable $=\Delta$ Bid-ask spread } \\
\hline & \multicolumn{2}{|c|}{ Pre-release } & \multirow{3}{*}{$\begin{array}{c}\text { Release } \\
(3) \\
{[0]}\end{array}$} & \multicolumn{2}{|c|}{ Post-release } \\
\hline & $(1)$ & $(2)$ & & (4) & $(5)$ \\
\hline & {$[-5,-1]$} & {$[-3,-1]$} & & {$[1,3]$} & {$[1,5]$} \\
\hline \multirow[t]{2}{*}{ News } & $-0.013^{*}$ & $-0.012 * *$ & $0.017 * * *$ & $0.016 * *$ & 0.004 \\
\hline & $(-1.71)$ & $(-1.98)$ & $(3.44)$ & $(2.13)$ & $(0.53)$ \\
\hline Controls & Yes & Yes & Yes & Yes & Yes \\
\hline Observations & 410,227 & 410,949 & 411,763 & 411,172 & 410,545 \\
\hline Adjusted R-squared & 0.026 & 0.017 & 0.006 & 0.016 & 0.024 \\
\hline Fixed effects & Yes & Yes & Yes & Yes & Yes \\
\hline Number of firms & 355 & 358 & 364 & 360 & 358 \\
\hline
\end{tabular}

Panel B: Quote count

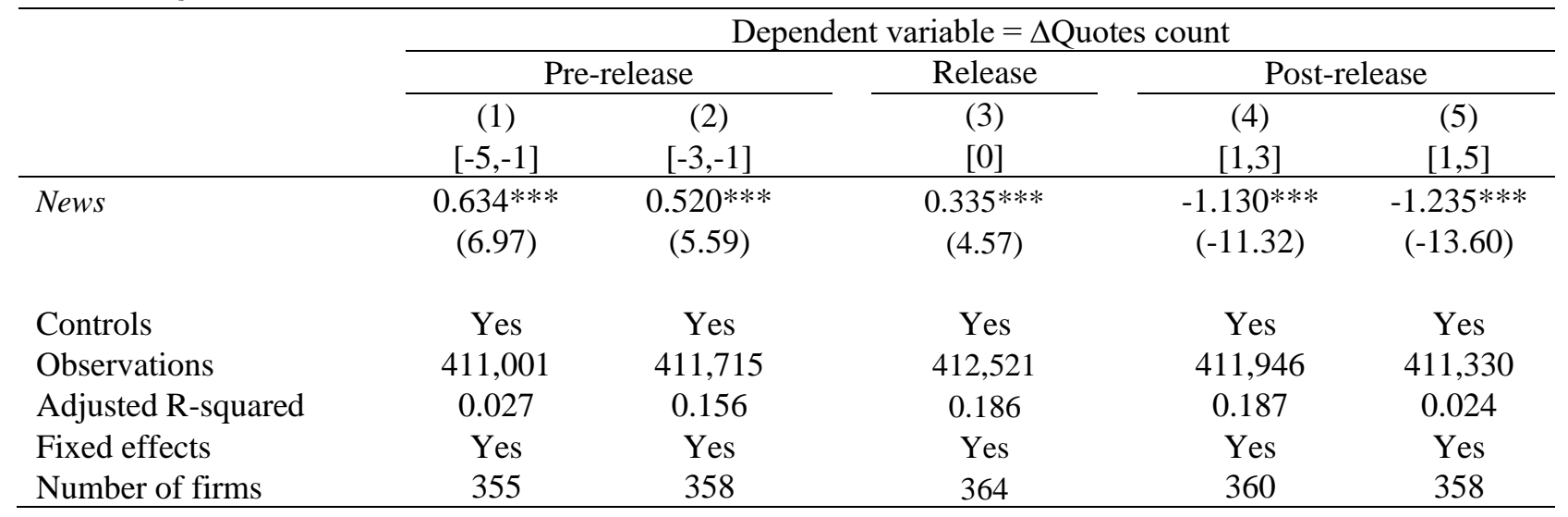


Panel C: Dealer count

\begin{tabular}{|c|c|c|c|c|c|}
\hline & \multicolumn{5}{|c|}{ Dependent variable $=\Delta$ Dealers count } \\
\hline & \multicolumn{2}{|c|}{ Pre-release } & \multirow{3}{*}{$\begin{array}{c}\text { Release } \\
(3) \\
{[0]}\end{array}$} & \multicolumn{2}{|c|}{ Post-release } \\
\hline & (1) & $(2)$ & & (4) & (5) \\
\hline & {$[-5,-1]$} & {$[-3,-1]$} & & {$[1,3]$} & {$[1,5]$} \\
\hline \multirow[t]{2}{*}{ News } & $0.039 * * *$ & $0.024 * * *$ & $0.011 * * *$ & $-0.045 * * *$ & $-0.056 * * *$ \\
\hline & $(7.70)$ & $(4.75)$ & $(2.78)$ & $(-9.10)$ & $(-9.92)$ \\
\hline Controls & Yes & Yes & Yes & Yes & Yes \\
\hline Observations & 411,001 & 411,715 & 412,521 & 411,946 & 411,330 \\
\hline Adjusted R-squared & 0.035 & 0.112 & 0.122 & 0.123 & 0.016 \\
\hline Fixed effects & Yes & Yes & Yes & Yes & Yes \\
\hline Number of firms & 355 & 358 & 364 & 360 & 358 \\
\hline
\end{tabular}




\section{Table 8 Subsample analysis: Characteristics of news and firms}

This table presents results from daily panel regressions that examine how news coverage affects CDS liquidity, conditioned on the characteristics of news and firms. Panel A is portioned by the direction of news sentiment. Panel B is portioned by the relevance of news to firm fundamentals. Panel C is portioned by whether the news is scheduled or not. Panel D is portioned by the sample median of total assets. In each panel, the dependent variables are change in CDS liquidity for the reference entity $i$ on news day $t$, measured as bid-ask spread in columns 1 and 2, the number of quotes in columns 3 and 4, and the number of dealers in columns 5 and 6. Ln(\#news) is the log of one plus the total number of stories published on the Dow Jones newswire on a given day. The control variables are described in table 1 . The regressions include firm, year-month, and day-ofthe-week fixed effects. Standard errors are clustered at the firm dimension and corrected for heteroskedasticity. t-statistics are reported in parentheses. ${ }^{*}, * *$, and $* * *$ indicate significance at the $10 \%, 5 \%$, and $1 \%$ levels, respectively.

Panel A: Negative and positive news

\begin{tabular}{|c|c|c|c|c|c|c|}
\hline \multirow[t]{3}{*}{ Dependent variable: } & \multicolumn{2}{|c|}{$\Delta$ Bid-ask spread } & \multicolumn{2}{|c|}{$\Delta$ Quotes count } & \multicolumn{2}{|c|}{$\Delta$ Dealers count } \\
\hline & Negative & Positive & Negative & Positive & Negative & Positive \\
\hline & (1) & (2) & (3) & (4) & (5) & (6) \\
\hline Ln(\#news) & $\begin{array}{c}0.052 * * * \\
(3.46)\end{array}$ & $\begin{array}{l}0.011 \\
(1.03)\end{array}$ & $\begin{array}{c}1.550 * * * \\
(5.84)\end{array}$ & $\begin{array}{c}1.317 * * * \\
(6.41)\end{array}$ & $\begin{array}{c}0.033 * * \\
(2.55)\end{array}$ & $\begin{array}{c}0.036^{* * * *} \\
(3.93)\end{array}$ \\
\hline Controls & Yes & Yes & Yes & Yes & Yes & Yes \\
\hline Observations & 28,276 & 46,203 & 28,333 & 46,260 & 28,333 & 46,260 \\
\hline Adjusted R-squared & 0.015 & 0.017 & 0.183 & 0.175 & 0.119 & 0.111 \\
\hline Fixed effects & Yes & Yes & Yes & Yes & Yes & Yes \\
\hline Number of firms & 354 & 355 & 355 & 355 & 355 & 355 \\
\hline \multicolumn{7}{|c|}{ Panel B: Hard and soft news } \\
\hline \multirow[t]{3}{*}{ Dependent variable: } & \multicolumn{2}{|c|}{$\Delta$ Bid-ask spread } & \multicolumn{2}{|c|}{$\Delta$ Quotes count } & \multicolumn{2}{|c|}{$\Delta$ Dealers count } \\
\hline & Hard & Soft & Hard & Soft & Hard & Soft \\
\hline & (1) & (2) & (3) & (4) & (5) & (6) \\
\hline Ln(\#news) & $\begin{array}{c}0.028^{* *} \\
(2.15)\end{array}$ & $\begin{array}{l}0.012 \\
(1.17)\end{array}$ & $\begin{array}{c}2.060 * * * \\
(8.20)\end{array}$ & $\begin{array}{c}0.270^{*} \\
(1.72)\end{array}$ & $\begin{array}{c}0.047 * * * \\
(4.11)\end{array}$ & $\begin{array}{l}0.006 \\
(0.66)\end{array}$ \\
\hline Controls & Yes & Yes & Yes & Yes & Yes & Yes \\
\hline Observations & 25,681 & 69,563 & 25,728 & 69,649 & 25,728 & 69,649 \\
\hline Adjusted R-squared & 0.020 & 0.012 & 0.163 & 0.182 & 0.106 & 0.115 \\
\hline Fixed effects & Yes & Yes & Yes & Yes & Yes & Yes \\
\hline Number of firms & 355 & 359 & 356 & 360 & 356 & 360 \\
\hline
\end{tabular}


Panel C: Unscheduled and scheduled news

\begin{tabular}{|c|c|c|c|c|c|c|}
\hline \multirow{3}{*}{ Dependent variable: } & \multicolumn{2}{|c|}{$\Delta$ Bid-ask spread } & \multicolumn{2}{|c|}{$\Delta$ Quotes count } & \multicolumn{2}{|c|}{$\Delta$ Dealers count } \\
\hline & Unscheduled & Scheduled & Unscheduled & Scheduled & Unscheduled & Scheduled \\
\hline & (1) & (2) & (3) & (4) & (5) & (6) \\
\hline Ln(\#news) & $\begin{array}{c}0.024 * * * \\
(2.90)\end{array}$ & $\begin{array}{l}0.041 \\
(1.60)\end{array}$ & $\begin{array}{c}1.446^{* * * *} \\
(8.32)\end{array}$ & $\begin{array}{c}1.393 * * * \\
(4.16)\end{array}$ & $\begin{array}{c}0.040 * * * \\
(5.26)\end{array}$ & $\begin{array}{l}0.013 \\
(0.75)\end{array}$ \\
\hline Controls & Yes & Yes & Yes & Yes & Yes & Yes \\
\hline Observations & 77,780 & 17,464 & 77,896 & 17,481 & 77,896 & 17,481 \\
\hline Adjusted R-squared & 0.010 & 0.017 & 0.177 & 0.163 & 0.115 & 0.102 \\
\hline Fixed effects & Yes & Yes & Yes & Yes & Yes & Yes \\
\hline Number of firms & 360 & 349 & 361 & 350 & 361 & 350 \\
\hline \multicolumn{7}{|c|}{ Panel D: Small and large firms } \\
\hline \multirow[t]{3}{*}{ Dependent variable: } & \multicolumn{2}{|c|}{$\Delta$ Bid-ask spread } & \multicolumn{2}{|c|}{$\Delta$ Quotes count } & \multicolumn{2}{|c|}{$\Delta$ Dealers count } \\
\hline & Small & Large & Small & Large & Small & Large \\
\hline & $(1)$ & $(2)$ & $(3)$ & $(4)$ & $(5)$ & $(6)$ \\
\hline Ln(\#news) & $\begin{array}{c}0.045^{* * *} * \\
(2.90)\end{array}$ & $\begin{array}{l}0.009 \\
(1.26)\end{array}$ & $\begin{array}{c}1.849 * * * \\
(6.93)\end{array}$ & $\begin{array}{c}0.975 * * * \\
(5.07)\end{array}$ & $\begin{array}{c}0.036^{* * *} * \\
(3.57)\end{array}$ & $\begin{array}{c}0.032 * * * \\
(3.47)\end{array}$ \\
\hline Controls & Yes & Yes & Yes & Yes & Yes & Yes \\
\hline Observations & 47,540 & 47,704 & 47,643 & 47,734 & 47,643 & 47,734 \\
\hline Adjusted R-squared & 0.011 & 0.010 & 0.163 & 0.188 & 0.105 & 0.119 \\
\hline Fixed effects & Yes & Yes & Yes & Yes & Yes & Yes \\
\hline Number of firms & 246 & 157 & 246 & 158 & 246 & 158 \\
\hline
\end{tabular}




\section{Table 9 Subsample analysis: Analyst rating changes}

This table presents results from regressions that examine how the arrival of analyst-rating news affects CDS liquidity. The dependent variable is the change in bid-ask spreads for the reference entity $i$ on news day $t$. In columns (1) and (2), News is a dummy variable that equals 1 if analyst rating change is downgrade, and 0 otherwise. In columns (3) and (4), News is a dummy variable that equals 1 if analyst rating change is neutral, and 0 otherwise. In columns (5) and (6), News is a dummy variable that equals 1 if analyst rating change is upgrade, and 0 otherwise. The control variables are described in table 1 . The regressions include firm, year-month, and day-of-theweek fixed effects. Standard errors are clustered at the firm dimension and corrected for heteroskedasticity. t-statistics are reported in parentheses. *, **, and *** indicate significance at the $10 \%, 5 \%$, and $1 \%$ levels, respectively.

\begin{tabular}{|c|c|c|c|c|c|c|}
\hline & \multicolumn{2}{|c|}{ Downgrade } & \multicolumn{2}{|c|}{ Neutral } & \multicolumn{2}{|c|}{ Upgrade } \\
\hline & $(1)$ & $(2)$ & (3) & $(4)$ & $(5)$ & $(6)$ \\
\hline News & $\begin{array}{l}0.018 \\
(0.68)\end{array}$ & $\begin{array}{l}0.011 \\
(0.40)\end{array}$ & $\begin{array}{l}0.004 \\
(0.13)\end{array}$ & $\begin{array}{c}-0.011 \\
(-0.38)\end{array}$ & $\begin{array}{c}-0.034^{*} \\
(-1.71)\end{array}$ & $\begin{array}{c}-0.033^{*} \\
(-1.67)\end{array}$ \\
\hline Controls & No & Yes & No & Yes & No & Yes \\
\hline Observations & 461,390 & 411,763 & 461,390 & 411,763 & 461,390 & 411,763 \\
\hline Adjusted R-squared & 0.003 & 0.006 & 0.003 & 0.006 & 0.003 & 0.006 \\
\hline Fixed effects & Yes & Yes & Yes & Yes & Yes & Yes \\
\hline Number of clusters & 392 & 364 & 392 & 364 & 392 & 364 \\
\hline
\end{tabular}

